\title{
Factors affecting the willingness of a segment of the Irish population to consume proteins from sustainable sources
}

\author{
A. Fitzpatrick ${ }^{1}$ and M. Dermiki ${ }^{1}$ \\ ${ }^{1}$ Faculty of Science, Department of Health and Nutritional Sciences, Institute of Technology Sligo, Ash Lane, F91 \\ YW50, Sligo, Ireland
}

Environmental, ethical and health issues linked with the consumption of meat have resulted in the investigation of proteins from sustainable sources. The aim of the current study was to investigate which factors affect the acceptability of these proteins.

An online questionnaire was developed and completed by 146 students and staff of an Institute of Technology in the west of Ireland. It included questions on the sociodemographic characteristics (age, gender, farming background, education level), meat consumption habits, frequency of meat consumption, food neophobia ${ }^{(1)}$, attachment to meat ${ }^{(2)}$, and acceptability of insects, single-cell organisms, in-vitro meat and plant-based proteins. Parametric and non-parametric statistical tests were employed to test the effect of the different factors on the acceptability of the protein sources under investigation ${ }^{(3)}$.

There was a negative correlation between acceptability of plant-based proteins and frequency of meat consumption (Spearman rho $=-0.180, p=0.030$ ), possibly due to attachment to meat. Frequency of meat consumption did not exert a significant effect on the acceptability of insects, single-cell organisms and in-vitro proteins. Mann-Whitney U test showed that participants who were from a farming background $(25 \%)$ were more likely to find the consumption of insects $(U=2577, p=0.005)$ and in-vitro proteins $(\mathrm{U}=2534, \mathrm{p}=0.01)$ unacceptable. Regarding gender, Mann-Whitney U test revealed that male participants $(34 \%)$ were more willing than females to consume insects $(U=2887.5, p=0.02)$, single-cell organisms $(U=2852.5, p=0.03)$ and in-vitro proteins $(U=3111.5$, $\mathrm{p}=0.001)$ which is in agreement with other studies $\left.{ }^{(2}\right]$. Moreover, men scored higher in meat attachment $(\mathrm{U}=1684, \mathrm{p}=0.005)$ compared to women. Age affected only the acceptability of single-cell organisms $(p=0.021)$, with younger people more likely to find their consumption unacceptable. These differences in acceptability of the different protein sources could not be attributed to food neophobia, since neophobia scores were not affected by the sociodemographic characteristics of the participants.

The results of the current study suggest that meat attachment and sociodemographic characteristics play a significant role in the choice of proteins from sustainable sources. These findings could possibly guide policy development and education towards the consumption of these proteins. However, further research is needed to corroborate these findings to a more representative sample of the Irish population.

1. Pliner P, Hobden K (1992) Appetite 19, 105-120.

2. Graça J, Calheiros MM, Oliveira A (2015) Appetite 95, 113-125.

3. Addinsoft (2020). XLSTAT statistical and data analysis solution.

4. Verbeke W (2015) Food Qual Prefer 39, 147-155. 